\title{
Clinical Profile and Outcome of Patients with Severe Acute Pancreatitis
}

\author{
Rishabh Sehgal ${ }^{\circledR 1}$, Inder Pal Singh ${ }^{\circledR 2}$, Jyotisterna Mittal ${ }^{\circledR 3}$ \\ ${ }^{1}$ Senior Resident, Department of Gastroentrology, Dayanand Medical College and Hospital, Ludhiana, Punjab, India, ${ }^{2}$ Senior Resident, Department of Medicine, \\ Government Medical College, Patiala, Punjab, India, ${ }^{3}$ Consultant Dermatologist, Fortis Hospital, Amritsar, Punjab, India.
}

\section{Abstract}

Background: Acute pancreatitis (AP) is an acute inflammatory condition of the pancreas leading to pancreatic autodigestion. The present study was conducted to study the clinical profile and outcome of patients with severe acute pancreatitis. Subjects \& Methods: The study was conducted on 40 patients of acute pancreatitis. Clinical profile including history, examination findings, etiology of pancreatitis, clinical severity (according to Modified Marshall Score, BISAP score, APACHE II, HAPS score, SOFA score) was recorded. Results: Severe Acute Pancreatitis (SAP) among patients. Majority of the patients i.e. $22(55 \%)$ had alcohol consumption as etiological factor causing SAP followed by biliary 10 $(25 \%) \&$ idiopathic $5(12.5 \%)$. Hypertriglyceridemia and drug-induced (herbal medication) pancreatitis was present in $1(2.5 \%)$ patient each. Out of all $1(2.5 \%)$, patients had a history of both alcohol consumption and the presence of gallstone as an etiological factor. 22 patients (55\%) out of 40 patients only conservative management was used while 18(45\%) patients underwent USG guided percutaneous drainage was done. Out of these 18 patients, $3(7.5 \%)$ patients required Laparoscopic Necrosectomy \& 2(5\%) patients required open necrosectomy in addition to ultrasound-guided PCD. Patients who improved had a mean BISAP SCORE of $2.15 \pm 0.54$, Modified Marshall score of $3.65 \pm 1.44$, APACHE II score of $9.77 \pm 4.45$, SOFA score $5.54 \pm 2.49$, RANSON's score $3.85 \pm 1.80$ and HAP score of $0.65 \pm 0.63$. Conclusion: Most common etiology of severe acute pancreatitis is alcohol followed by biliary etiology. Out of severity scores (BISAP, APACHE-II, SOFA, HAPS), only BISAP score $\geq 3$ is predictive of poor outcome in patients with severe acute pancreatitis.

Keywords: Acute pancreatitis, APACHE II, Severity scores

Corresponding Author: Inder Pal Singh, Senior Resident, Department of Medicine, Government Medical College, Patiala, Punjab, India. E-mail: drinderpal@gmail.com

Received: 14 August 2020

Revised: 10 September 2020

Accepted: 24 September 2020

Published: 06 October 2020

\section{Introduction}

Acute pancreatitis (AP) is an acute inflammatory condition of the pancreas leading to pancreatic autodigestion $\&$ is caused by the activation of proteolytic enzymes in pancreatic acini itself. It is a common disease with wide clinical variation and increasing incidence. The incidence of acute pancreatitis ranges from 4.8-24.2 cases per 100000 populations in England, Denmark \& the United States. ${ }^{[1]}$

Acute pancreatitis is stratified into three categories of clinical severity: mild, moderately severe, and severe acute pancreatitis. Severe acute pancreatitis (SAP) is characterized by the persistence of organ failure $\geq 48$ hours. ${ }^{[2]}$ Severe acute pancreatitis (SAP) develops in about $25 \%$ of patients with acute pancreatitis. Severe acute pancreatitis is characterized by extensive pancreatic inflammation and/or necrosis and is followed by a systemic inflammatory response syndrome (SIRS) that may lead to multiple organ dysfunction syndromes (MODS) within the first week. Overall mortality in severe acute pancreatitis is $15-20 \%$. ${ }^{[3]}$

The prediction of severity is an important component in the management of acute pancreatitis as patients require intensive care and monitoring. The scoring systems such as Bedside Index for Severity in Acute Pancreatitis (BISAP), Acute Physiology and Chronic Health Evaluation II (APACHE II), Harmless Acute Pancreatitis Score (HAPS), Sequential organ failure assessment (SOFA) have been developed to predict severe pancreatitis. ${ }^{[4]}$ These scoring systems all have a high false-positive rate, are complex and cumbersome. Other parameters have also been correlated with the severity of pancreatitis such as Hematocrit $>44 \%$, Blood urea nitrogen level $>20 \mathrm{mg} / \mathrm{dl}$, Creatinine level $>1.8 \mathrm{mg} / \mathrm{dl}$ and the presence of SIRS during the first 24-48 hours to identify patients who are at greatest risk for severe disease and most likely to benefit from a high-intensity nursing unit. Evidence of necrosis on CECT also is a risk factor for the development of severe 
acute pancreatitis. ${ }^{[5]}$ Therefore, the radiological scores like Computed tomography severity index (CTSI) and modified CTSI are also used to predict severe pancreatitis. The present study was conducted to study the clinical profile and outcome of patients with severe acute pancreatitis.

\section{Subjects and Methods}

The study was conducted in DMCH to study the clinical profile including nutritional, biochemical and radiological profile and outcome of the patients admitted with severe acute pancreatitis after clearance by the institutional ethical committee. Informed consent was obtained from the patients. After fulfilling the following inclusion and exclusion criteria, a total of 40 patients were selected as a part of the study.

Demographic data, the clinical profile including history, examination findings, etiology of pancreatitis, clinical severity (according to Modified Marshall Score, BISAP score, APACHE II, HAPS score, SOFA score), perfusion status (including type of I/V fluids, amount, baseline CVP \& Urine Output, CVP \& Urine Output at $72 \mathrm{hrs}$ ), analgesics used (type and duration), antibiotics used (type and duration), the nutritional profile of the patient including BMI, anthropometric measurements, Mini Nutritional Assessment score, type and duration of enteral feed. Biochemical profile including routine and individually ordered investigations such as hemogram, RFT, LFT, Coagulation profile, RBS, LDH, S. Amylase, S. Lipase, CRP, S. Calcium, S. Magnesium, S. Phosphorous, ABG analysis, Procalcitonin levels etc. The Final Outcome of the patient was recorded. Data were described in terms of range; mean \pm standard deviation ( $\pm \mathrm{SD}$ ). A probability value (p-value) less than 0.05 was considered statistically significant.

\section{Results}

\begin{tabular}{|lll|}
\hline \multicolumn{3}{|c|}{ Table 1: Distribution of patients as per Age \& Gender } \\
\hline Variables & Number & $\%$ \\
\hline Age (in years) & & \\
$18-40$ & 27 & 67.5 \\
$40-60$ & 9 & 22.5 \\
$>55$ & 4 & 10 \\
\hline Male: Female & $34: 6$ & $85: 15$ \\
\hline
\end{tabular}

[Table 1] shows that out of 40 patients $27(67.5 \%)$ patients were in the age group of $18-40$ years, $9(22.5 \%)$ patients were in the 40-60 years group while $4(10 \%)$ were aged $>60$ years. The mean age of patients was $40.3 \pm 14.9$ years. The majority of the patients were male $34(85 \%)$ and females were only 6 $(15 \%)$.
Table 2: Etiology of Severe Acute Pancreatitis (SAP) among patients

\begin{tabular}{|lll|}
\hline Etiology of SAP & Number & $\mathbf{\%}$ \\
\hline Alcohol & 22 & 55 \\
\hline Biliary & 10 & 25 \\
\hline Idiopathic & 5 & 12.5 \\
\hline Alcohol \& Biliary & 1 & 2.5 \\
\hline Drug-induced & 1 & 2.5 \\
\hline Hypertriglyceridemia & 1 & 2.5 \\
\hline
\end{tabular}

[Table 2] depicts the etiology of Severe Acute Pancreatitis (SAP) among patients. Majority of the patients i.e. 22 (55\%) had alcohol consumption as etiological factor causing SAP followed by biliary $10(25 \%) \&$ idiopathic $5(12.5 \%)$. Hypertriglyceridemia and drug-induced (herbal medication) pancreatitis was present in $1(2.5 \%)$ patient each. Out of all 1 $(2.5 \%)$, the patient had a history of both alcohol consumption and the presence of gallstone as an etiological factor.

\begin{tabular}{lll|}
\hline \multicolumn{2}{l}{ Table 3: Anagement plan among patients } \\
\hline Management plan used & Number & $\mathbf{\%}$ \\
\hline Conservative & 22 & 55 \\
Conservative + PCD* & 18 & 45 \\
Conservative + Endoscopic & 0 & 0 \\
PCD +Laparoscopic Surgical & 3 & 7.5 \\
necrosectomy & & \\
PCD + Open Surgical Necro- & 2 & 5 \\
sectomy & & \\
\hline
\end{tabular}

[Table 3] shows that in 22 patients (55\%) out of 40 patients only conservative management was used while 18(45\%) patients underwent USG guided percutaneous drainage was done. Out of these 18 patients, $3(7.5 \%)$ patients required Laparoscopic Necrosectomy \& 2(5\%) patients required open necrosectomy in addition to ultrasound-guided PCD.

\begin{tabular}{|lll|}
\hline \multicolumn{2}{|l|}{ Table 4: Final outcome of patients } \\
\hline Final outcome & Number & $\%$ \\
\hline DAMA & 9 & 22.5 \\
Expired & 5 & 12.5 \\
Improved & 26 & 65 \\
\hline
\end{tabular}

[Table 4] shows that out of a total of 40 patients admitted with severe acute pancreatitis 26 patients $(65 \%)$ were improved and were discharged. 5 patients (12.5\%) expired and 9 patients $(22.5 \%)$ were discharged against medical advice. Both expired and DAMA was considered to be poor outcomes. 


\begin{tabular}{lllll}
\hline \multicolumn{7}{l}{ Table 5: Association of various clinical severity scores (mean) with the final outcome } \\
\hline & Improved & Poor Outcome & t & p-value \\
& Mean \pm SD & Mean \pm SD & & \\
BISAP score & $2.15 \pm 0.54$ & $2.71 \pm 0.91$ & -2.440 & 0.02 \\
Modified Marshall & $3.65 \pm 1.44$ & $4.29 \pm 1.49$ & -1.308 & 0.19 \\
\hline APACHE II & $9.77 \pm 4.45$ & $15.50 \pm 8.71$ & -2.770 & 0.01 \\
\hline SOFA score & $5.54 \pm 2.49$ & $5.86 \pm 2.11$ & -0.407 & 0.68 \\
\hline RANSON's score & $3.85 \pm 1.80$ & $4.79 \pm 1.67$ & -1.610 & 0.11 \\
\hline HAP score & $0.65 \pm 0.63$ & $1.07 \pm 0.73$ & -1.894 & 0.06 \\
\hline
\end{tabular}

[Table 5] shows that patients who improved had a mean BISAP SCORE of $2.15 \pm 0.54$, Modified Marshall score of $3.65 \pm$ 1.44, APACHE II score of $9.77 \pm 4.45$, SOFA score 5.54 \pm 2.49 , RANSON's score $3.85 \pm 1.80$ and HAP score of $0.65 \pm 0.63$.

[Table 6] shows the association of mean CT severity scores at admission with the outcome. Mean CT severity score in patients who improved was $7.64 \pm 2.59$ and in patients with poor outcomes, the CT severity score was $6.50 \pm 3.51$. There was no statistically significant association between CT severity index and outcome $(\mathrm{p}=0.39)$.

\section{Discussion}

Out of 40 patients, 27 (67.5\%) patients were in the age group of $18-40$ years, $9(22.5 \%)$ patients were in the $40-60$ years group while $4(10 \%)$ were aged $>60$ years. The mean age of patients was $40.3 \pm 14.9$ years. Similar results were given by Santvoort et al, ${ }^{[6]}$ who stated the maximum number of patients were aged below 45 years with a mean age of 40.3 years. In the present study majority of the patients were males $34(85 \%)$ and females were only $6(15 \%)$. This is consistent with Pandol et al, ${ }^{[7]}$ who found $82 \%$ of subjects to be males.

The present study reported the majority of the patients i.e. $22(55 \%)$ had alcohol consumption as an etiological factor causing SAP followed by biliary $10(25 \%) \&$ idiopathic 5 (12.5\%). Hypertriglyceridemia and drug-induced pancreatitis were present in $1(2.5 \%)$ patient each.

In the present study, all 40 patients had a modified Marshall Score of $\geq 2$ \& mean Marshall Score was $3.9 \pm 1.5$. Out of 40 BISAP scores of $\geq 3$ was present in 14 (35\%) patients and $<3$ was seen in $26(65 \%)$ patients. The mean BISAP score in all 40 patients was $2.4 \pm 0.7$. APACHE II score of $\geq 8$ was present in $29(72.5 \%)$ patients and in 11 patients $(27.5 \%)$ it was less than 8 . The mean APACHE II score in all 40 patients was 11.8 \pm 6.8 . HAPS score of $\geq 1$ was present in 26 patients $(65 \%)$ at admission while 0 score was present in 14 patients $(35 \%)$ and the mean score was $0.8 \pm 0.7$. RANSON score $\geq 3$ was present in 30 patients $(75 \%)$ and $<3$ in 10 patients $(25 \%)$ and the mean score was $4.2 \pm 1.8$. SOFA score was also calculated in all patients, the mean score was $5.7 \pm 2.3$ with a range from 3-12. Howard et al, ${ }^{[8]}$ reported that out of 31 patients with SAP $74.19 \%$ had BISAP score $\geq 2$ and $25.81 \%$ had BISAP score $<2$. APACHE II score of $\geq 8$ and $<8$ was present in $80.65 \%$ and $19.35 \%$ patients with SAP respectively. $83.9 \%$ had RANSON score $\geq 3$ and $16.13 \%$ had RANSON score $<3$. Patel et al, ${ }^{[9]}$ reported that out of 40 patients with SAP, $37.5 \%$ patients had a BISAP score $\geq 3,80 \%$ had RANSON score $>3$, $65 \%$ had APACHE II score $\geq 8$.

The present study reported that out of a total of 40 patients admitted with severe acute pancreatitis 26 patients $(65 \%)$ were improved and were discharged. 5 patients (12.5\%) expired and 9 patients $(22.5 \%)$ were discharged against medical advice. The study shows no statically significant association of age, gender \& etiological factor with the outcome with $\mathrm{p}=0.58$, $0.31 \& 0.47$ respectively. The results of the study are supported by Rao et al. ${ }^{[10]}$

The findings of the present study show that patients with BISAP score $\geq 3$ had significantly poor outcome than with score $<3(\mathrm{p}=0.03)$ but APACHE II score $\geq 8$, RANSON score $\geq 3 \&$ HAP score $\geq 1$ did not have any statistically significant poorer outcome than patients with values lower than these cut-offs ( $p=0.52,0.25,0.18$ respectively). Baig et al, ${ }^{[11]}$ reported out of 159 patients with BISAP score $\leq 2$ mortality was present in $3(1.9 \%)$ patients. Since the present study shows BISAP score at admission $\geq 3$ and maximum PCT during hospitalization were significantly correlating with the outcome, therefore, the association between these parameters was studied in the present study and found a significant association between these two $(\mathrm{p}=0.03)$. Patients with BISAP score $\geq 3$ had significantly higher PCT levels during hospitalization. As PCT is a marker of the presence of infection, patients with BISAP score $\geq 3$ had a higher probability of developing an infection during a hospital stay. The present study shows that the mean CT severity score in patients who improved was $7.64 \pm 2.59$ and in patients with poor outcome was $6.50 \pm 3.51$. There was no statistically significant association between CT severity index and mortality $(p=0.39)$. Similar results were reported by 
Table 6: Association of Mean CT severity scores at admission with the outcome

\begin{tabular}{|c|c|c|c|c|}
\hline CT Severity scores & Improved & Poor Outcome & $\mathbf{t}$ & p-value \\
\hline & Mean \pm SD & Mean \pm SD & & \\
\hline & $7.64 \pm 2.59$ & $6.50 \pm 3.51$ & 0.876 & 0.39 \\
\hline
\end{tabular}

Singla et al. ${ }^{[12][13]}$

\section{Conclusions}

The most common etiology of severe acute pancreatitis is alcohol followed by biliary etiology. Out of severity scores (BISAP, APACHE-II, SOFA, HAPS), only BISAP score $\geq 3$ is predictive of poor outcome in patients with severe acute pancreatitis. Early NJFT feeding in severe acute pancreatitis leads to improved outcomes.

\section{References}

1. Forsmark CE, Vege SS, Wilcox CM. Acute Pancreatitis. N Engl J Med. 2016;375(20):1972-1981. Available from: https: //dx.doi.org/10.1056/nejmra1505202.

2. Johnson CD, Besselink MG, Carter R. Acute pancreatitis. BMJ. 2014;349:4859. Available from: https://dx.doi.org/10.1136/ bmj.g4859.

3. Lankisch PG, Apte M, Banks PA. Acute pancreatitis. Lancet. 2015;386(9988):85-96. Available from: https://dx.doi.org/10. 1016/s0140-6736(14)60649-8.

4. Meier RF, Beglinger C. Nutrition in pancreatic diseases. Best Pract Res Clin Gastroenterol. 2006;20(3):507-529. Available from: https://dx.doi.org/10.1016/j.bpg.2006.01.004.

5. Makhija R, Kingsnorth AN. Cytokine Storm in acute pancreatitis. J Hepatobiliary Pancreat Surg. 2002;9(4):401411. Available from: https://doi.org/10.1007/s005340200049.

6. van Santvoort HC, Besselink MG, Bakker OJ, Hofker HS, Boermeester MA, Dejong $\mathrm{CH}$, et al. Step-up Approach or Open Necrosectomy for Necrotizing Pancreatitis. N Engl J Med. 2010;362(16):1491-502. Available from: https://doi.org/ 10.1056/nejmoa0908821.

7. Pandol SJ, Saluja AK, Imrie CW, Banks PA. Acute Pancreatitis: Bench to the Bedside. Gastroenterology. 2007;132(3):1127-1151. Available from: https://dx.doi.org/10. 1053/j.gastro.2007.01.055.

8. Howard JM, Hess W, Traverso W. Johann Georg Wirsüng (1589-1643) and the pancreatic duct: the prosector of Padua, Italy. J Am Coll Surg. 1998;187(2):201-211. Available from: https://dx.doi.org/10.1016/s1072-7515(98)00136-7.

9. Patel S, Patel T, Hada D, Suvera M, Parmar H. Clinical profile and outcome of acute pancreatitis and necrotizing pancreatitis. IAIM. 2015;2(7):116-136.

10. Rao BS, Vani MS, Chandra VS. Etiology, clinical profile, severity and outcome of acute pancreatitis in relation to bedside index for severity of acute pancreatitis BISAP and CTSI scores. Int J Med Res Health Sci. 2014;3(4):922-922. Available from: http://dx.doi.org/10.5958/2319-5886.2014.00026.5.

11. Maharaul HH, Dhorajia D. A single institute study of clinical profile of acute pancreatitis. Indian journal of applied research. 2015;5(10):700-702.

12. Baig SJ, Abdur Rahed SS. A prospective study of the aetiology, severity and outcome of acute pancreatitis in Eastern India. Trop Gastroenterol . 2008;29(1):20-22.

13. Singla SK, Jain NP, Gupta S, Virk SS, Attri PI, Sethi P. Clinical profile and outcome of severe acute pancreatitis. NJIRM. 2013;4(6):71-75.

Copyright: (C) the author(s), 2020. It is an open-access article distributed under the terms of the Creative Commons Attribution License (CC BY 4.0), which permits authors to retain ownership of the copyright for their content, and allow anyone to download, reuse, reprint, modify, distribute and/or copy the content as long as the original authors and source are cited.

How to cite this article: Sehgal R, Singh IP, Mittal J. Clinical Profile and Outcome of Patients with Severe Acute Pancreatitis. Asian J. Med. Res. 2020;9(3):8-11.

DOI: dx.doi.org/10.47009/ajmr.2020.9.3.ME2

Source of Support: Nil, Conflict of Interest: None declared. 